\title{
Dipeptidyl Peptidase-4 Inhibitor-Associated Bullous Pemphigoid
}

\author{
Kaisa Tasanen ${ }^{1 *}$, Outi Varpuluoma ${ }^{1}$ and Wataru Nishie ${ }^{2}$ \\ ${ }^{1}$ PEDEGO Research Unit, Department of Dermatology, Medical Research Center Oulu, Oulu University Hospital, \\ University of Oulu, Oulu, Finland, ${ }^{2}$ Department of Dermatology, Hokkaido University Graduate School of Medicine, Sapporo, \\ Japan
}

OPEN ACCESS

Edited by:

Ralf J. Ludwig,

Universität zu Lübeck, Germany

Reviewed by:

Unni Samavedam,

University of Cincinnati, United States

Marian Dmochowski,

Poznan University of Medical

Sciences, Poland

Stephanie Goletz,

Universität zu Lübeck, Germany

*Correspondence:

Kaisa Tasanen

kaisa.tasanen@oulu.fi

Specialty section:

This article was submitted to Autoimmune and Autoinflammatory

Disorders,

a section of the journal

Frontiers in Immunology

Received: 01 April 2019

Accepted: 16 May 2019

Published: 04 June 2019

Citation:

Tasanen K, Varpuluoma O and

Nishie W (2019) Dipeptidy

Peptidase-4 Inhibitor-Associated

Bullous Pemphigoid.

Front. Immunol. 10:1238.

doi: 10.3389/fimmu.2019.01238
Bullous pemphigoid (BP) is an organ-specific autoantibody-mediated blistering skin disease that mainly affects the elderly. Typical clinical features include the widespread blisters, often preceded by and/or associated with itchy urticarial or eczema-like lesions. BP patients have circulating autoantibodies against BP180 and/or the plakin family protein BP230 both of which are components of hemidesmosomes in basal keratinocytes. Most BP autoantibodies particularly target the epitopes within the non-collagenous NC16A domain of BP180. Clinical findings and murine models of BP have provided evidence of a pathogenic role of anti-NC16A autoantibodies. However, it is largely unknown what triggers the breakage of immunotolerance against BP180 in elderly individuals. The incidence of BP has been increased over the past two decades in several countries. Aside from aging populations, the factors behind this phenomenon are still not fully understood. Neurodegenerative diseases such as multiple sclerosis, Parkinson's disease, and certain dementias are independent risk factors for BP. Recently several case reports have described $\mathrm{BP}$ in patients with diabetes mellitus (DM) patients who have been treated with dipeptidyl peptidase-4 inhibitors (DPP-4i or gliptins), which are a widely used class of anti-DM drugs. The association between the use of DPP-4is, particularly vildagliptin, and BP risk has been confirmed by several epidemiological studies. Evidence suggests that cases of gliptin-associated BP in Japan display certain features that set them apart from cases of "regular" BP. These include a "non-inflammatory" phenotype, targeting by antibodies of different immunodominant BP180 epitopes, and a specific association with the human leukocyte antigen (HLA) types. However, recent studies in European populations have found no major differences between the clinical and immunological characteristics of gliptin-associated BP and "regular" BP. The DPP-4 protein (also known as CD26) is ubiquitously expressed and has multiple functions in various cell types. The different effects of the inhibition of DPP-4/CD26 activity include, for example, tissue modeling and regulation of inflammatory cells such as T lymphocytes. Although the pathomechanism of gliptin-associated BP is currently largely unknown, investigation of the unique effect of gliptins in the induction of BP may provide a novel route to better understanding of how immunotolerance against BP180 breaks down in BP.

Keywords: BP180, bullous pemphigoid, CD26, collagen XVII, diabetes mellitus, DPP4, gliptins 


\section{CLINICAL, HISTOLOGICAL, AND IMMUNOLOGICAL FEATURES OF BP}

Typically, elderly BP patients have tense blisters, erosions, crusts and erythema over their entire body (Figure 1A). Before the development of blisters, BP is often preceded by a prodromal phase, characterized by severe pruritus and/or non-specific skin symptoms, which may include eczematous, urticarial, papular or excoriated lesions. As many as $20-30 \%$ of BP patients have no blistering, and this can delay or hamper correct diagnosis $(2,3)$.

Histopathologically, BP blisters form in the subepidermis and contain numerous eosinophilic infiltrates (Figure 1B). A diagnosis of $\mathrm{BP}$ is based on clinical manifestations, direct biopsy (Figure 1C) and indirect (Figure 1D) immunofluorescence (IF) microscopy on salt split human skin and serological assays [BP180-NC16A enzyme-linked immunosorbent assay (ELISA)]. The direct IF study, which is the gold standard of BP diagnostics, reveals the linear deposition of IgG and/or complement $\mathrm{C} 3$ at the dermal-epidermal junction of perilesional skin (Figure 1C).

\section{PATHOGENESIS OF BP}

BP autoantibodies target BP180 and BP230, both of which are hemidesmosomal proteins that play essential roles in maintaining stable adhesion between the epidermis and the dermis (Figure 2) $(4,5)$. Also known as collagen XVII, BP180 is a $180 \mathrm{kD}$ type II-orientated transmembrane collagen with its amino terminus located in the cytoplasm and its carboxyl terminus in the extracellular matrix (Figure 2). BP230 is a 230 $\mathrm{kD}$ protein of the plakin family that is found in the cytoplasm. Around $85 \%$ of BP immunoglobulin (Ig)G autoantibodies target the juxtamembranous extracellular non-collagenous (NC16A) domain of BP180 and levels of anti-NC16A correlate well with the severity of BP $(4,5)$. Passive transfer of anti-BP180 NC16A domain IgG autoantibodies from BP patients induces skin fragility in transgenic mice that express human $\mathrm{BP} 180(6,7)$, suggesting that the anti-NC16A autoantibodies play a central role in blister formation. In contrast, the significance of anti-BP230 autoantibodies is unclear. In addition to IgG autoantibodies, BP patients also have IgE-class autoantibodies, which are thought to be associated with the inflammatory characteristics of BP (8). The binding of BP autoantibodies to their epitopes activates complement, which leads to the degranulation of mast cells and the release of leukotrienes, TNF- $\alpha$ and other cytokines $(4,5)$. These mediators activate neutrophils and eosinophils, which produce proteolytic enzymes that are able to degrade the dermo-epidermal junction, which has the end result of blister formation $(4,5)$.

\section{EPIDEMIOLOGY OF BP}

\section{Incidence, Comorbidities, and Mortality}

Estimates of the annual incidence of BP range between 2.5 and 21.7 cases per million persons (9-11). For example, the agestandardized incidence of BP has been reported as 14 per million person-years in both Finland and Scotland $(12,13)$. Several studies have reported a trend of increased incidence of BP over the last few decades, including some that controlled for the effects of an aging population $(12,14)$.

$\mathrm{BP}$ is an atypical autoimmune disease because it normally develops in the elderly; reports of the mean age at diagnosis vary between 69 and 83 years $(10,14-20)$. Since BP is a disease most commonly seen in elderly patients, $\mathrm{BP}$ is frequently accompanied by several comorbidities (21). A recent study found that $84 \%$ of subjects with BP also had at least two other chronic diseases (22). Hypertension, psoriasis and diabetes are among the most common comorbidities (22-25). Reports of associations between $\mathrm{BP}$ and malignancies are inconsistent. A recent meta-analysis found that BP was not associated with overall cancer morbidity, although there was an association between BP and hematological malignancies (26).

Patients with BP have a heightened risk of death. An overall 1year mortality rate of $23.5 \%$ in patients with BP (range 6-41\%) was reported in a recent systematic review and meta-analysis (27). Advanced age at BP onset, diagnostic delay and comorbid diabetes are each associated with increased 1-year mortality (19). Polypharmacy is common among BP patients and it has been associated with higher mortality: the more drugs a BP patients receives, the greater their mortality risk (17).

\section{Neurological Diseases Increase the Risk of BP}

Several epidemiological studies indicate that neurological and neurodegenerative diseases are common in BP patients (21, 28-30). More specifically, multiple sclerosis (MS), Parkinson's disease (PD) and certain dementias, including Alzheimer's disease (AD), significantly increase an individual's risk of developing BP $(28,29)$. BP180 and a neural isoform of BP230 are expressed in the brain as well as in the skin (31). The strong epidemiological association between neurological disorders and $\mathrm{BP}$, alongside the neuronal expression of $\mathrm{BP}$ autoantigens has led to the assumption that neurodegeneration or neuroinflammation could lead to the failure of self-tolerance against BP180 and BP230 and thus the development of BP (32-34). Some patients with $\mathrm{AD}$, MS or $\mathrm{PD}$ have circulating autoantibodies against BP180, but these non-pathogenic autoantibodies do not bind to the skin and therefore do not cause cutaneous symptoms (3234). Currently it is not known whether epitope spreading or some other mechanism or factors lie behind the high risk of BP carried by neurological patients. A recent nationwide Finnish registry study suggested that the use of some drugs that affect the nervous system may contribute to the onset of BP, but additional studies are required to confirm this association (35).

\section{Medication As a Risk Factor for BP}

To date, more than 60 drugs have been reported to induce $\mathrm{BP}$, including certain antibiotics, diuretics and other antihypertensive drugs, anti-TNF- $\alpha$-drugs and vaccines (36). Of all drug classes, robust evidence suggests that prior use of dipeptidylpeptidase-4 inhibitors (DPP-4i or gliptins) carries the highest risk for BP. Currently there is a rapidly growing volume of publications regarding DPP-4i-associated BP (Tables 1, 2), meaning that it is now an important issue in the field. 
A

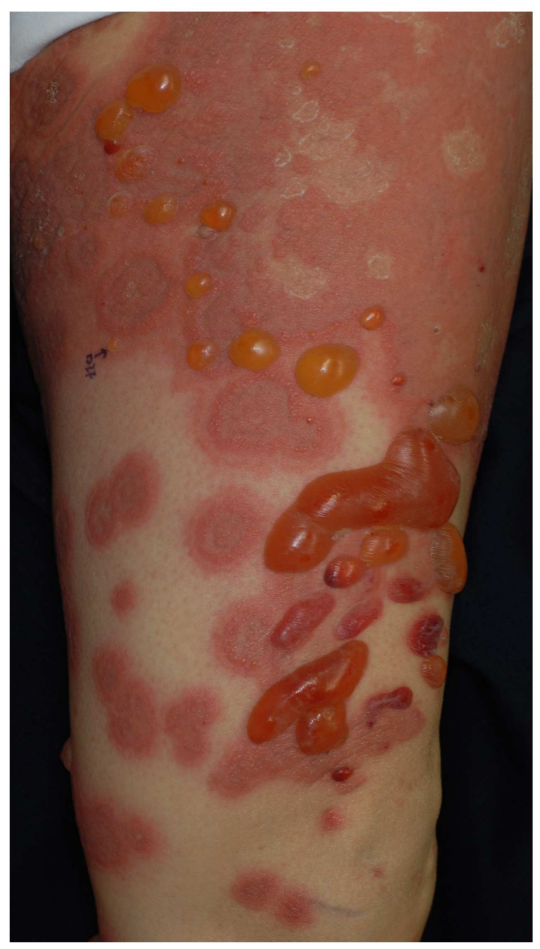

B

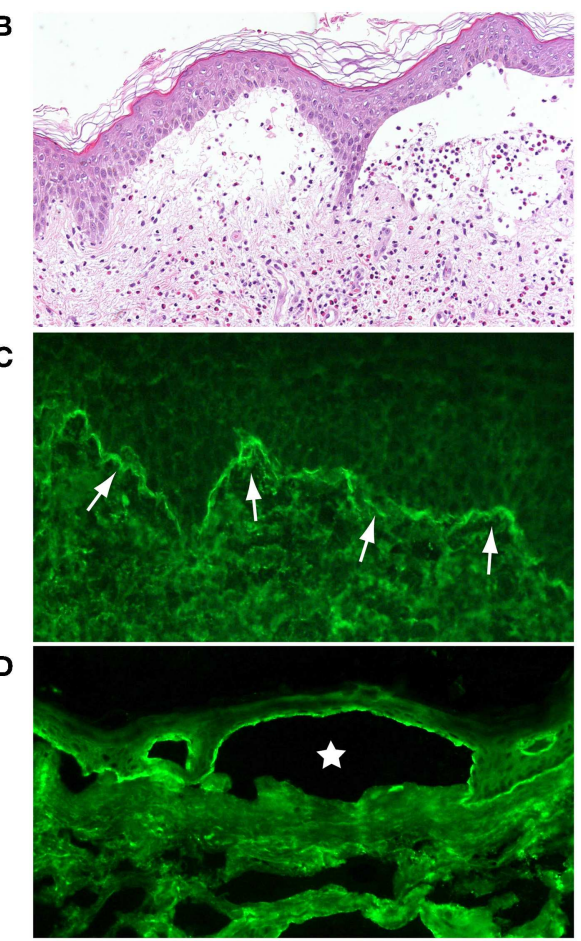

FIGURE 1 | (A) Typical BP patient who had widespread itchy urticarial and erythematous lesions and tense blisters. (B) The histopathological analysis of lesional skin samples shows subepidermal blisters with numerous eosinophilic infiltrates. (C) Direct IF of a peri-blistering lesion reveals the linear deposition of IgG at the dermo-epidermal junction (arrows). (D) Indirect IF detects circulating IgG autoantibodies directing the dermo-epidermal junction of normal salt-split human skin. The IgG reacts with the roof epidermis of an artificial blister (star). This figure has been previously published in the following paper: Nishie (1). New diagnostic tool for bullous pemphigoid: full-length BP180 ELISA.

In addition immune checkpoint inhibitors against programmed death-1 (anti-PD-1) and programmed deathligand 1 (anti-PD-L1) have recently been added to the list of drugs associated with BP $(59,60)$. Anti-PD-1 and -PD-L1 medications are used to treat metastatic melanoma and other advanced malignancies. As many as $20 \%$ of treated patients develop dermatological adverse events, predominantly nonspecific rashes and pruritus (60). Since 2015, there have been at least 29 case reports of an association between treatment with anti-PD-1/PD-L1 medication and $\mathrm{BP}(60)$. A recent retrospective study of 853 patients found BP in $0.8 \%$ of patients treated with PD-1 or PD-L1 inhibitors (59).

\section{DPP-4i-ASSOCIATED BP DPP-4}

The DPP-4 protein is a member of the prolyl-oligopeptidase superfamily, which between them cleave a wide range of bioactive peptides (61). DPP-4 (also known as CD26) is ubiquitously expressed in various kinds of cells, including T-lymphocytes (62). The expression of the DPP-4/CD26 protein is increased in several skin diseases, including such as T-cell lymphomas, psoriasis, lichen planus and atopic dermatitis (63). The cutaneous expression of DPP-4/CD26 was recently shown to be upregulated in BP patients, but independently of prior gliptin treatment (52).

\section{DPP-4 Inhibitors: A Widely Used Drug Class for the Treatment of Type II Diabetes Mellitus}

Among other substrates DPP-4 degrades incretins, a group of metabolic hormones, two of which are glucagon-like peptide1 (GLP-1) and glucose-dependent insulinotropic polypeptide (GIP) $(64,65)$. Inhibition of the enzymatic activity of DPP4 prolongs the GLP-1/GIP-dependent secretion of insulin by pancreatic beta cells that is induced by increased serum glucose levels. Therefore, DPP-4is have beneficial effects on blood glucose levels, but their use does not carry a relevant risk of hypoglycemia. In addition to its effects on GLP-1 and GIP, DPP-4 is also involved in the N-terminal dipeptide cleavage of various molecules including eotaxin (CCL11), regulated on activation, normal T-cell expressed and secreted (RANTES), CCL5, CXCL9, CXCL10, and CXCL11 (64). Thus, DPP4-is may have functions other than their anti-hyperglycemic effects. It has also been reported that DPP-4is may promote regeneration following endothelial and myocardial injury, and may inhibit the development of atherosclerosis (66). Furthermore, DPP-4is may target other proteins in the DPP family, including DPP-8 and DPP-9, whose biological functions have not yet been fully elucidated (65). Since 2006, when sitagliptin became the first DPP-4i to be licensed, more than 10 other DPP-4is have been approved for clinical use. 


\section{A}

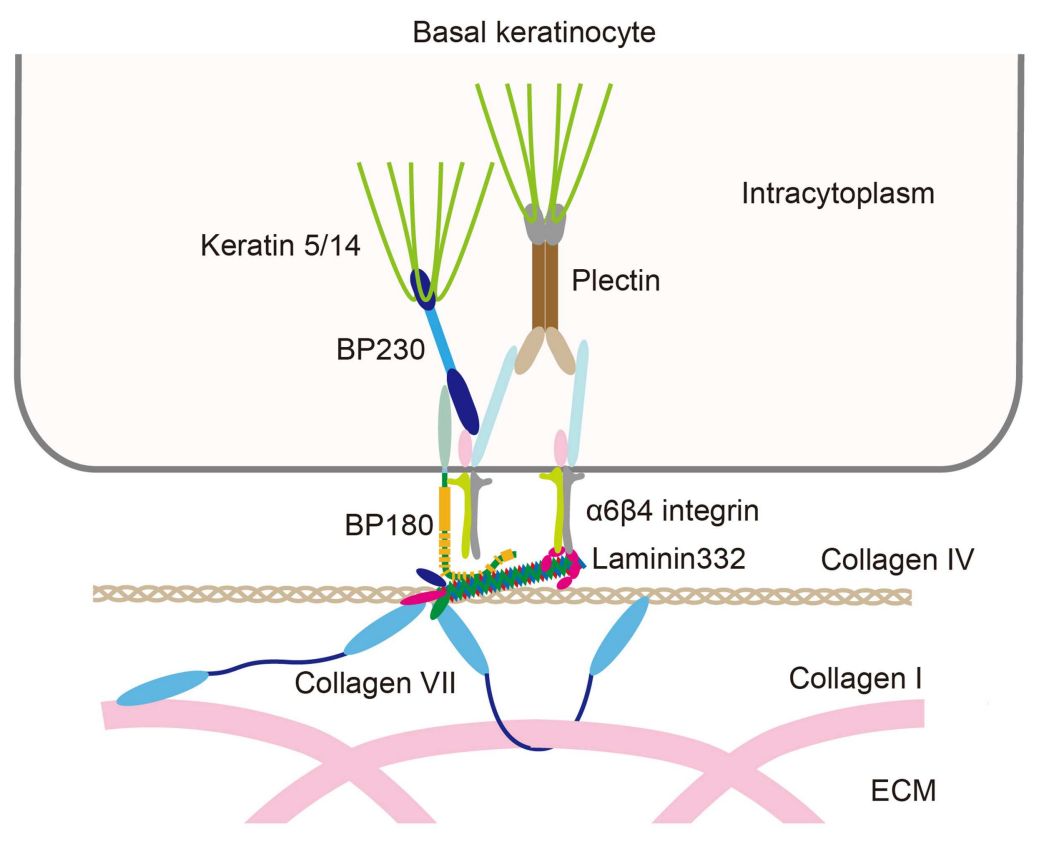

B

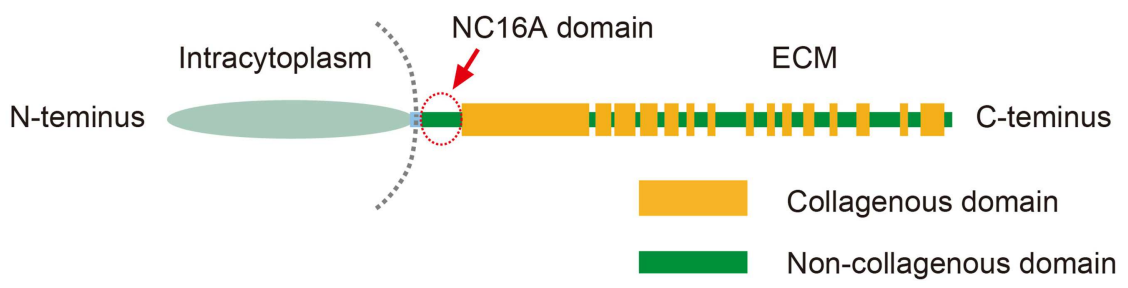

FIGURE 2 | (A) Schematic presentation of molecules that make up the dermo-epidermal junction. (B) The structure of BP180. Note that the NC16A domain (arrow) is the juxtamembranous extracellular domain. This figure has been previously published in the following paper: Nishie (4). Update on the pathogenesis of bullous pemphigoid: an autoantibody-mediated blistering disease targeting collagen XVII.

\section{Case Reports of DDP-4i-Associated BP}

Skandalis et al. (38) were the first researchers to describe gliptinassociated BP. They reported five cases in which BP arose following use of DPP-4i and metformin for periods lasting between 2 and 13 months. Since then, numerous case reports of DPP-4i-associated BP have been published originating from different countries and concerning all the available DPP-4i drugs (Table 1).

\section{Registry and Cohort Studies Showing the Association Between the Use of DPP-4i Medication and BP}

There is an impressive body of epidemiological evidence showing the association between the use of DPP-4i medication and BP (Table 2). Reports from European and French pharmacovigilance databases were the first epidemiological studies to show a disproportionately high incidence of BP in patients treated with DPP-4is $(43,67)$. A study using reports filed in the EudraVigilance pharmacovigilance database found that BP was associated with treatment with vildagliptin, linagliptin, saxagliptin, and sitagliptin (43). Vildagliptin was the DPP-4i most commonly reported to induce BP. A similar disproportionality was also noted in a Japanese pharmacovigilance database study, particularly among patients treated with vildagliptin, linagliptin, and teneligliptin (68).

In a Swiss case-controlled study of 23 diabetic BP patients and 170 diabetic controls DPP-4i use was more frequent in the diabetic BP patients than the controls (39.1 and 33.5\%, respectively) although the difference did not reach statistical significance (50). Another case-controlled study of $61 \mathrm{BP}$ patients with diabetes and 122 diabetic controls found that DPP-4i use increased the risk of BP almost 3-fold, but the increase was driven by vildagliptin rather than the other DPP-4is (53). An Israeli casecontrolled study of $82 \mathrm{BP}$ patients also found that vildagliptin was the DPP-4i most strongly associated with BP risk, although it also found an increased risk for BP with linagliptin (56). The first nationwide registry study from Finland demonstrated a 10-foldelevated risk of BP after the use of vildagliptin in a case-controlled setting (54). In that study combination therapy with metformin 
TABLE 1 | Selected case reports of gliptin-associated bullous pemphigoid.

\begin{tabular}{|c|c|c|c|}
\hline First author & $\begin{array}{l}\text { Number } \\
\text { of cases }\end{array}$ & DPP-4 inhibitor used (n) & $\begin{array}{l}\text { Latency } \\
\text { time }\end{array}$ \\
\hline Pasmatzi et al. (37) & 2 & Vildagliptin (2) & 2 months \\
\hline Skandalis et al. (38) & 6 & Vildagliptin (5), sitaglitpin (1) & 2-13 months \\
\hline Aouidad et al. (39) & 3 & Vildagliptin (1), sitagliptin (2) & 5-6 months \\
\hline Attaway et al. (40) & 1 & Sitagliptin (1) & 12 months \\
\hline Bene et al. (41) & 3 & Vildagliptin (3) & 1-37 months \\
\hline Mendonça et al. (42) & 3 & Vildaglitpin (2), linagliptin (1) & $\begin{array}{l}45 \text { days }-3 \\
\text { months }\end{array}$ \\
\hline García et al. (43) & 1 & Vildagliptin & 12 months \\
\hline Haber et al. (44) & 2 & Linagliptin (2) & 3-4 months \\
\hline Sakai et al. (45) & 1 & Linagliptin (1) & 9 months \\
\hline Esposito et al. (46) & 1 & Linagliptin (1) & 5 months \\
\hline Yoshiji et al. (47) & 5 & $\begin{array}{l}\text { Vildaglitpin (1), linagliptin (2), } \\
\text { sitagliptin (1), anagliptin (1) }\end{array}$ & $1-15$ months \\
\hline Harada et al. (48) & 1 & Sitagliptin (1) & 3 years \\
\hline Oya et al. (49) & 1 & Anagliptin (1) & 1 month \\
\hline Schaffer et al. (50) & 9 & Vildagliptin (4), sitagliptin (5) & 5-48 months \\
\hline Fania et al. (51) & 5 & $\begin{array}{l}\text { Vildagliptin (1), sitagliptin (1), } \\
\text { linagliptin (2), alogliptin (1) }\end{array}$ & $1-8$ months \\
\hline Lindgren et al. (52) & 10 & $\begin{array}{l}\text { Vildagliptin (4), sitagliptin (5), } \\
\text { linagliptin (1) }\end{array}$ & 5-24 months \\
\hline
\end{tabular}

and vildagliptin or sitagliptin was associated with an increased risk of $\mathrm{BP}$, but no such association was seen with metformin alone (54). Another nationwide study from Korea also found that the use of DPP-4is was associated with a significant increase in the risk of developing BP; with vildagliptin again presenting the highest risk (58). Accordingly, a recent French study found that the observed per-capita intake of DPP4is, particularly that of vildagliptin was higher in a cohort of 1,787 patients with $B P$ than in the general population (57).

\section{Clinical and Immunological Characteristics of DPP-4i-Associated BP}

The reported latency between the initiation of DPP-4i medication and a diagnosis of BP is generally several months, but may be more than 1 year (Table 1) $(43,53,54,56,57)$. The long latency between the initiation of a gliptin and the onset of BP suggests that, rather than being simply an adverse reaction to treatment, gliptin-associated BP should in fact be viewed as a drug-aggravated disease. Only a few studies have described the clinical course of DPP-4i-associated BP. In a study by Benzaquen et al. (53) with a follow-up period of 3-30 months, $95 \%$ of patients whose DPP-4i therapy was discontinued achieved partial or complete BP remission, while only seen in $55 \%$ of those who continued DPP-4i therapy. The population of a recent French study comprised 108 BP patients $45.3 \%$ of whose DPP4i treatment was stopped, with treatment being continued in the remaining $54.7 \%$. The study found no differences between the groups in the median time to achieve disease control, the time to first relapse, the relapse rate, or the mean initial dose of clobetasol propionate cream for the treatment of BP (57). Overall, contradictory findings remain regarding the effect of
DPP-4i discontinuation on BP disease course, and further study is required.

Some studies have suggested that DPP-4i-BP occurs more commonly in men and in individuals over 80 years old (53, $56,58,67)$, but not all studies have found such gender or age differences $(54,57)$. A cohort study from Israel reported that mucous membrane involvement is more likely in DPP-4iassociated BP than in patients without prior DPP-4i exposure (56). Although some distinct clinical features have been reported in cases of gliptin-associated BP, most European studies have concluded that there are no major clinical and immunological differences between DPP-4i-BP and non-DPP-4i-DP $(57,69)$.

Interestingly, certain Japanese DPP4i-associated BP patients do have distinct clinical and immunological features (70). Firstly, DPP-4i-associated BP in Japanese patients tends to show a noninflammatory phenotype with less erythema than that seen in typical BP (71) (Figure 3). The low level of inflammation is associated with low numbers of lesional infiltrated eosinophils (70). Secondly, around $40-70 \%$ of Japanese patients with DPP-4i-associated BP have a negative or low titer for antiBP180 NC16A autoantibodies (70-72). This is a sharp contrast to the 80 to $90 \%$ of non-DPP-4i-associated BP cases, who are positive for anti-BP180 NC16A autoantibodies (73). In Japanese DPP-4i-associated BP cases, autoantibodies mainly target the mid-portion of the non-NC16A extracellular domain of BP180. It is therefore impossible to detect such autoantibodies using a commercially available kit (70). Similarly to some European cohorts, aged males feature prominently among the Japanese DPP-4i-associated BP population (68), but any elevated likelihood of mucous membrane involvement is still uncertain. However, it should be noted that not all Japanese DPP-4iassociated BP patients show such distinct features, and a cohort study from Kurume University reported that an investigation of BP patients who tested negative for anti-BP180 NC16A autoantibodies revealed no association with prior DPP-4i use (74). Future studies may reveal why distinct clinical and immunological features are observed in some Japanese cases of DPP-4i-associated BP.

\section{Genetic Characteristics of DPP-4i-Associated BP}

The unique clinical and immunological characteristics seen in some Japanese patients with DPP4i-associated BP poses the question as to whether these patients have distinct genetic characteristics, such as particular human leukocyte antigen (HLA) haplotypes. This question was recently addressed by Ujiie et al. (72), in a study on 30 Japanese patients with DPP4i-associated BP. Based on their BP Disease Area Index (BPDAI) scores (75), the patients were divided into two groups: inflammatory, and non-inflammatory. Most patients (21/30) showed the non-inflammatory phenotype and low levels of anti-NC16A BP180 autoantibodies. Interestingly, 86\% (18/21) of the non-inflammatory patients had the HLA-DQB1*03:01 haplotype, whereas that allele was present in only $31 \%(19 / 61)$ of the diabetes patients receiving DPP-4i without any blister formations. The results clearly suggest that HLA-DQB1*03:01 
TABLE 2 | Epidemiological studies of gliptin-associated bullous pemphigoid.

\begin{tabular}{|c|c|c|c|c|c|}
\hline First author & Country & Population & Cases/controls, $\mathbf{n}$ & Mean age (cases), y & Adjusted OR \\
\hline Schaffer et al. (50) & Switzerland & Hospital data & 23 (DM+BP)/170(DM) & 77.6 & DPP-4i: 2.48 (95\% Cl 0.75-8.3) \\
\hline Benzaquen et al. (53) & France & Hospital data (3 hospitals) & 61 (BP+DM)/122(DM) & 79.1 & $\begin{array}{l}\text { DPP-4i: } 2.64 \text { (95\% Cl 1.19-5.85) } \\
\text { Vildagliptin: } 3.57(95 \% \text { Cl 1.07-11.84) } \\
\text { Sitagliptin: } 2.13(95 \% \text { Cl 0.77-5.89) } \\
\text { Linagliptin/saxagliptin: } 2.90 \\
\text { (95\% Cl 0.47-17.74) }\end{array}$ \\
\hline Varpuluoma et al. (54) & Finland & Nationwide registry data & $3397 / 12941$ & 76.6 & $\begin{array}{l}\text { DPP-4i: } 2.19 \text { (95\% Cl 1.55-3.11) } \\
\text { Vildagliptin: } 10.4(95 \% \mathrm{Cl} 4.56-23.80) \\
\text { Sitagliptin: } 1.37 \text { (95\% Cl 0.93-2.01) } \\
\text { Metformin: } 1.05 \text { (95\% Cl 0.88-1.24) }\end{array}$ \\
\hline Kawaguchi et al. (55) & Japan & Hospital data & $\begin{array}{l}168 \text { cases: } \\
\text { DPP4i-BP } 32 \\
\text { non-DPP4i-BP } 136\end{array}$ & 79.7 & $N A^{a}$ \\
\hline Kridin and Bergman (56) & Israel & Hospital data & $82(\mathrm{BP}+\mathrm{DM}) / 328$ (DM) & 79.1 & $\begin{array}{l}\text { DPP-4i: } 3.16 \text { (95\% Cl 1.86-5.37) } \\
\text { Vildagliptin: } 10.67 \text { (95\% Cl 5.09-22.36) } \\
\text { Linagliptin: } 6.65 \text { (95\% Cl 2.24-19.72) } \\
\text { Sitagliptin: } 0.42 \text { (95\% Cl 0.12-1.45) }\end{array}$ \\
\hline Plaquevent et al. (57) & France & $\begin{array}{l}\text { Hospital data ( } 21 \\
\text { hospitals). general } \\
\text { population from } \\
\text { reimbursement register }\end{array}$ & $1787 / 225412$ & 77.9 & $N A^{b}$ \\
\hline Lee et al. (58) & Korea & Insurance data, nationwide & $\begin{array}{l}670(\mathrm{BP}+\mathrm{DM}) / \\
670(\mathrm{DM})\end{array}$ & 75.3 & $\begin{array}{l}\text { DPP-4i: } 1.58 \text { (95\% Cl 1.25-2.00) } \\
\text { Vildagliptin: } 1.81 \text { (95\% Cl 1.31-2.50) } \\
\text { Sitagliptin: } 1.70 \text { (95\% Cl 1.19-2.43) } \\
\text { Linagliptin: } 1.64 \text { (95\% Cl 1.15-2.33) } \\
\text { Other DPP-4is: } 1.25 \\
\text { (95\% Cl 0.73-2.14) }\end{array}$ \\
\hline
\end{tabular}

BP, Bullous pemphigoid; Cl, Confidence interval; DM, Diabetes mellitus; DPP-4i, Dipeptidyl peptidase-4 inhibitor; OR, Odds ratio.

${ }^{a} \mathrm{BP}$ incidence $0.0859 \%$ of patients receiving DPP-4is.

${ }^{b}$ Observed frequency of DPP-4is and vildagliptin compared to general population (6.0 vs. 3.6\% and 3.3 vs. $0.7 \%$ ).

in non-inflammatory DPP-4i-BP is strongly associated with drug-related autoimmune disease (72). Although this study was performed on Japanese BP patients, HLA-DQB1*03:01 is also known to be associated with mucous membrane pemphigoid in Caucasian patients (76). Mucous membrane pemphigoid target non-NC16A extracellular domains of BP180 (77), as do DPP4iassociated BP autoantibodies. Therefore, it would be particularly interesting to determine whether HLA-DQB1*03:01 is also linked to non-inflammatory DPP4i-associated BP in Caucasian patients. However, a very recent study from Finland failed to detect such an association (52).

\section{Epitope-Spreading Phenomena in DPP-4i-Associated BP}

Models of BP have demonstrated important roles of anti-BP180 NC16A autoantibodies in blister formation $(6,7)$, while possible pathogenic roles of other autoantibodies targeting the nonNC16A regions of BP180 and BP230 have yet to be identified. However, the presence in DPP-4-associated BP of autoantibodies that target the non-NC16A regions of BP180 suggests that such antibodies may indeed also be pathogenic. Furthermore, antiBP180 NC16A autoantibodies may not play a primary role in the pathogenesis of DPP-4i-associated BP. A study of four DPP$4 \mathrm{i}$-associated BP patients whose clinical manifestations showed them to have the inflammatory phenotype found that these patients already had polyclonal $\operatorname{IgG}$ and $\operatorname{IgE}$ autoantibodies targeting various regions of BP180 including the NC16A and intracellular domains, as well as non-NC16A extracellular regions (51). These observations led the notion that the activity of anti-BP180 NC16A autoantibodies may be a secondary rather than a primary phenomenon, arising from epitope-spreading. Recently, several cases of DPP-4i-associated BP have been reported, in which anti-BP180 NC16A autoantibodies developed during the course of the disease (78-80). Interestingly, these case may initially have shown the non-inflammatory phenotype typically associated with autoantibodies directed against the nonNC16A domain of BP180, but their clinical characteristics later changed to a profile consistent with that of the inflammatory phenotype. Furthermore, cessation of DPP-4i treatment did not arrest disease progression, suggesting that the treatment may have triggered the disease, which was then set on a drugindependent course (79).

\section{Pathogenesis of DPP-4i-Associated BP}

Currently the pathogenesis of DPP-4i-associated BP remains largely unclear, but it may be reasonable to expect that the inhibition of CD26 expression on T-cells may have certain effects on the immune system. A murine model showed that inhibition of DPP-4 induces the infiltration of eosinophils into the skin (81). This is notable because the cutaneous infiltration of eosinophils is 


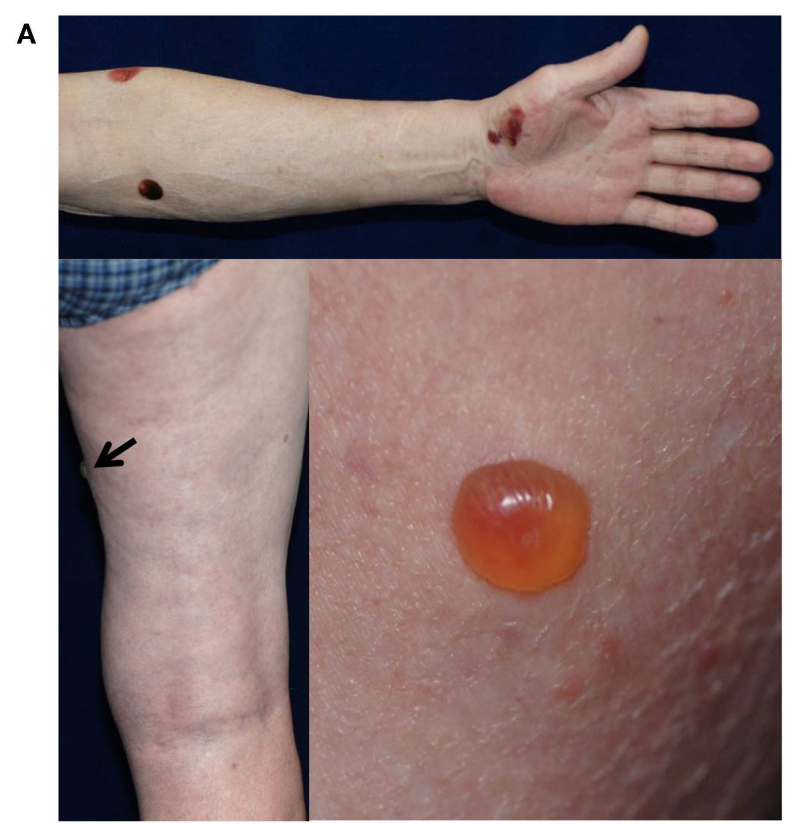

$\mathbf{B}$

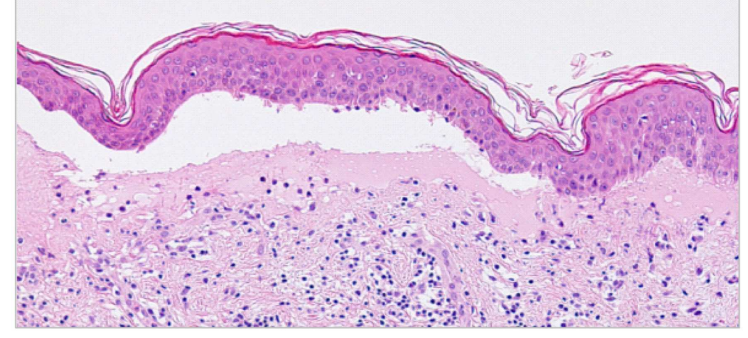

FIGURE 3 | (A) A case of DPP4i-BP in a 70-year-old man without autoantibodies directed against the NC16A domain of BP180. The patient had IgG autoantibodies against the non-NC16A domains of BP180. Note that there is no erythema around the blisters. (B) The histopathological analysis of lesional skin shows subepidermal blisters with low number of infiltrating eosinophils.

a typical histopathologic feature of BP. However, the numbers of infiltrating eosinophils in perilesional skin are somewhat lower in non-inflammatory Japanese DPP-4i-associated BP than in cases with the inflammatory phenotype $(70,72)$.

The major BP autoantigen BP180 is a transmembrane collagen; therefore, certain effects of DPP-4i on the biological activity or metabolism of BP180 may be involved in breaking immunotolerance of BP180. However, a very recent study found no significant effects of DPP4i on the expression or shedding of BP180 in keratinocytes in vitro (52). It should also be noted that DPP-4 is a cell-surface plasminogen receptor that converts plasminogen to plasmin, a major serine protease (82). Plasmin is known to cleave BP180 into its 120 and $97 \mathrm{kD}$ ectodomains $(83,84)$. Therefore, the suppression of DPP-4 may be associated with the development of epitopes for DPP-4i-BP autoantibodies, a possibility that needs to be elucidated by future studies.

It is mysterious that immunotolerance to BP180 is selectively broken in certain individuals by DPP-4i exposure, especially in HLA-DQB1*03:01 Japanese carriers (72). It is also curious why
BP180 is the only autoantigen for any autoimmune blistering diseases that is targeted by autoimmunity. Although a case of pemphigus vulgaris developing 6 months after the treatment with sitagliptin has been reported (85), BP accounts for the majority of cases of autoimmune blistering diseases likely associated with DPP-4i treatments. Autoimmune blistering diseases, particularly $\mathrm{BP}$, are disproportionately common in DM patients treated with a DPP-4i.

There are several hypothetical mechanisms that may be involved in the breakdown of immunotolerance to BP180, including aberrant expression of BP180 associated with abnormal post-translational modifications or homeostasis. Regarding with this notion, a recent study reported that saxagliptin and sitagliptin both induced epithelial-mesenchymal transition (EMT) in immortalized human keratinocytes (HaCaT), which is associated with increased migration and accelerated wound closure (86). BP180 is known to be involved in keratinocyte migration $(87,88)$, and EMT may exert an effect on various basement membrane proteins including BP180 (89). Thus, it is possible that DPP-4 inhibition influences keratinocytes in an EMT-dependent manner. It has also been reported that in vitro suppression of DPP-4-like activity in fibroblasts inhibits the TGF$\beta$-dependent proliferation of fibroblasts and the secretion of type I procollagen (90).

The final question is whether DPP-4i medication alone is sufficient to induce BP or if other factors are also required. It is currently unknown whether concomitant autoimmune diseases increase the BP risk of BP in gliptin-treated diabetics, since published studies have not yet compared the comorbidities of DPP4i-associated BP patients with those of non-DPP-4i-BP patients. In $\mathrm{BP}$, various triggering factors other than drugs have been reported; including infections, ultraviolet exposure and physical factors such as burns (91). Interestingly, there exists a report of BP having been induced by a thermal burn in a patient who was receiving DPP-4i treatment. In this case, cessation of the DPP-4i led to remission without the use of a systemic corticosteroid (92). The report suggests that DPP-4i treatment may increase the risk of BP but in this case did not independently induce the disease. The results of a French cohort study also suggested that DPP-4i treatment may trigger, but not induce BP (57).

\section{FUTURE PROSPECTS}

Despite the rapidly growing volume of papers regarding the association between the use of gliptins and BP, experimental and clinical data remain scarce. It remains to be seen whether the use of gliptins has any influence on the development of blistering or its severity in BP mouse models. Existing BP models are probably not suitable for this purpose because of the duration of gliptin use required to promote the breakage of immunological tolerance to BP180. On the other hand, we predict that the careful clinical, immunological and genetic characterization of patients with DPP-4i-associated BP will offer valuable information concerning autoimmunity against BP180 and may lead to the development of better treatments for all patients with BP (93). 


\section{CONCLUSIONS}

Recently published epidemiological data have confirmed firmly that gliptin treatment is a major factor in BP pathogenesis in patients from different ethnic backgrounds. The long latency period between the initiation of gliptin treatment and the beginning or diagnosis of BP suggests that DPP-4i-associated $\mathrm{BP}$ is a drug-aggravated, rather than a drug-induced, skin disorder. However, the pathomechanism behind this interesting phenomenon is currently unknown and it remains to be investigated whether gliptins predispose elderly individuals to $\mathrm{BP}$ by, for example, disturbing the balance of the immune system and/or altering the structures of the cutaneous basement membrane zone. We need more information concerning the phenotype and prognosis of gliptin-associated BP, and especially concerning the necessity of replacing gliptins with other DM

\section{REFERENCES}

1. Nishie W. New diagnostic tool for bullous pemphigoid: full-length BP180 ELISA. Pract Dermatol. (2017) 39:14-9.

2. Della Torre R, Combescure C, Cortes B, Marazza G, Beltraminelli H, Naldi L. Clinical presentation and diagnostic delay in bullous pemphigoid: a prospective nationwide cohort. Br J Dermatol. (2012) 167:1111-7. doi: 10.1111/j.1365-2133.2012.11108.x

3. Lamberts A, Meijer JM, Jonkman MF. Nonbullous cutaneous pemphigoid: a systematic review. J Am Acad Dermatol. (2018) 78:989-95.e2. doi: 10.1016/j.jaad.2017.10.035

4. Nishie W. Update on the pathogenesis of bullous pemphigoid: an autoantibody-mediated blistering disease targeting collagen XVII. J Dermatol Sci. (2014) 73:179-86. doi: 10.1016/j.jdermsci.2013.12.001

5. Schmidt E, Zillikens D. Pemphigoid diseases. Lancet. (2013) 381:320-32. doi: 10.1016/S0140-6736(12)61140-4

6. Liu Z, Sui W, Zhao M, Li Z, Li N, Thresher R. Subepidermal blistering induced by human autoantibodies to BP180 requires innate immune players in a humanized bullous pemphigoid mouse model. J Autoimmunity. (2008) 31:331-8. doi: 10.1016/j.jaut.2008.08.009

7. Nishie W, Sawamura D, Goto M, Ito K, Shibaki A, McMillan JR. Humanization of autoantigen. Nat Med. (2007) 13:378. doi: 10.1038/nm1496

8. Ujiie H. IgE autoantibodies in bullous pemphigoid: supporting role, or leading player? J Dermatol Sci. (2015) 78:5-10. doi: 10.1016/j.jdermsci.2015.03.002

9. Baican A, Baican C, Chiriac G, Chiriac MT, Macovei V, Zillikens D. Pemphigus vulgaris is the most common autoimmune bullous disease in northwestern Romania. Int J Dermatol. (2010) 49:768-74. doi: $10.1111 / j .1365-4632.2009 .04345$

10. Joly P, Baricault S, Sparsa A, Bernard P, Bedane C, Duvert-Lehembre S. Incidence and mortality of bullous pemphigoid in France. J Invest Dermatol. (2012) 132:1998-2004. doi: 10.1038/jid.2012.35

11. Kridin K, Ludwig RJ. The growing incidence of bullous pemphigoid: overview and potential explanations. Front Med. (2018) 5:220. doi: 10.3389/fmed.2018.00220

12. Försti A, Jokelainen J, Timonen M, Tasanen K. Increasing incidence of bullous pemphigoid in northern Finland: a retrospective database study in Oulu university hospital. Br J Dermatol. (2014) 171:1223-6. doi: 10.1111/bjd.13189

13. Gudi VS, White MI, Cruickshank N, Herriot R, Edwards SL, Nimmo F. Annual incidence and mortality of bullous pemphigoid in the Grampian region of north-east Scotland. Br J Dermatol. (2005) 153:424-7. doi: $10.1111 /$ j.1365-2133.2005.06662.x

14. Langan SM, Smeeth L, Hubbard R, Fleming KM, Smith CJP, West J. Bullous pemphigoid and pemphigus vulgaris-incidence and mortality in the UK: population based cohort study. BMJ. (2008) 337:a180. doi: 10.1136/bmj.a180

15. Brick KE, Weaver CH, Lohse CM, Pittelkow MR, Lehman JS, Camilleri MJ. Incidence of bullous pemphigoid and mortality of patients with bullous medications in patients with BP. Finally, we sincerely believe that further characterization of gliptin-associated BP will improve our understanding of autoimmunity in general.

\section{AUTHOR CONTRIBUTIONS}

All authors listed have made a substantial, direct and intellectual contribution to the work, and approved it for publication.

\section{FUNDING}

The study was supported in by the Academy of Finland (294738 to KT), the Sigrid Juselius Foundation (to KT), the Medical Research Center Oulu (to OV) and Oulu University Hospital (to $\mathrm{OV}$ and $\mathrm{KT}$ ). pemphigoid in Olmsted county, Minnesota, 1960 through 2009. J Am Acad Dermatol. (2014) 71:92-9. doi: 10.1016/j.jaad.2014.02.030

16. Cai S, Allen JC, Lim YL, Chua SH, Tan SH, Tang M. Mortality of bullous pemphigoid in Singapore: risk factors and causes of death in 359 patients seen at the national skin centre. Br J Dermatol. (2014) 170:1319-26. doi: $10.1111 /$ bjd. 12806

17. Försti A, Jokelainen J, Timonen M, Tasanen K. Risk of death in bullous pemphigoid: a retrospective database study in Finland. Acta DermatoVenereol. (2016) 96:758-61. doi: 10.2340/00015555-2347

18. Gual A, Mascaró JM, Rojas-Farreras S, Guilabert A, Julia M, Iranzo P. Mortality of bullous pemphigoid in the first year after diagnosis: a retrospective study in a Spanish medical centre. J Eur Acad Dermatol Venereol. (2014) 28:500-6. doi: $10.1111 /$ jdv.12065

19. Lee JH, Kim S. Mortality of patients with bullous pemphigoid in Korea. J Am Acad Dermatol. (2014) 71:676-83. doi: 10.1016/j.jaad.2014. 05.006

20. Marazza G, Pham HC, Scharer L, Pedrazzetti PP, Hunziker T, Trueb RM. Incidence of bullous pemphigoid and pemphigus in Switzerland: a 2-year prospective study. Br J Dermatol. (2009) 161:861-8. doi: $10.1111 / j .1365-2133.2009 .09300 . x$

21. Bech R, Kibsgaard L, Vestergaard C. Comorbidities and treatment strategies in bullous pemphigoid: an appraisal of the existing litterature. Front Med. (2018) 5:238. doi: 10.3389/fmed.2018.00238

22. Sim B, Fook-Chong S, Phoon YW, Koh HY, Thirumoorthy T, Pang SM. Multimorbidity in bullous pemphigoid: a case-control analysis of bullous pemphigoid patients with age- and gender-matched controls. J Eur Acad Dermatol Venereol. (2017) 10:1709-14. doi: 10.1111/jdv.14312

23. Jeon HW, Yun SJ, Lee S, Won YH, Lee J. Mortality and comorbidity profiles of patients with bullous pemphigoid in Korea. Ann Dermatol. (2018) 30:13-9. doi: $10.5021 /$ ad.2018.30.1.13

24. Kibsgaard L, Rasmussen M, Lamberg A, Deleuran M, Olesen AB, Vestergaard C. Increased frequency of multiple sclerosis among patients with bullous pemphigoid: a population-based cohort study on comorbidities anchored around the diagnosis of bullous pemphigoid. Br J Dermatol. (2017) 176:148691. doi: 10.1111/bjd.15405

25. Phan K, Goyal S, Murrell DF. Association between bullous pemphigoid and psoriasis: systematic review and meta-analysis of case-control studies. Aust J Dermatol. (2019) 60:23-8. doi: 10.1111/ajd.12899

26. Atzmony L, Mimouni I, Reiter O, Leshem YA, Taha O, Gdalevich M. Association of bullous pemphigoid with malignancy: a systematic review and meta-analysis. J Am Acad Dermatol. (2017) 77:691-9. doi: 10.1016/j.jaad.2017. 05.006

27. Kridin K, Shihade W, Bergman R. Mortality in patients with bullous pemphigoid: a retrospective cohort study, systematic review and metaanalysis. Acta Dermato-Venereol. (2019) 99:72-7. doi: 10.2340/000155 55-2930 
28. Försti A, Huilaja L, Schmidt E, Tasanen K. Neurological and psychiatric associations in bullous pemphigoid-more than skin deep? Exp Dermatol. (2017) 26:1228-34. doi: 10.1111/exd.13401

29. Lai YC, Yew YW, Lambert WC. Bullous pemphigoid and its association with neurological diseases: a systematic review and meta-analysis. J Eur Acad Dermatol Venereol. (2016) 30:2007-15. doi: 10.1111/jdv.13660

30. Langan SM, Groves RW, West J. The relationship between neurological disease and bullous pemphigoid: a population-based case-control study. $J$ Invest Dermatol. (2011) 131:631-6. doi: 10.1038/jid.2010.357

31. Seppänen A. Collagen XVII: a shared antigen in neurodermatological interactions? Clin Dev Immunol. (2013) 2013:240570. doi: $10.1155 / 2013 / 240570$

32. Kokkonen N, Herukka SK, Huilaja L, Kokki M, Koivisto AM, Hartikainen P. Increased levels of the bullous pemphigoid BP180 autoantibody are associated with more severe dementia in Alzheimer's disease. J Invest Dermatol. (2017) 137:71-6. doi: 10.1016/j.jid.2016.09.010

33. Messingham KA, Aust S, Helfenberger J, Parker KL, Schultz S, McKillip J. Autoantibodies to collagen XVII are present in parkinson's disease and localize to tyrosine-hydroxylase positive neurons. J Invest Dermatol. (2016) 136:721. doi: 10.1016/j.jid.2015.12.005

34. Tuusa J, Lindgren O, Tertsunen H, Nishie W, Kokkonen N, Huilaja L. BP180 autoantibodies target different epitopes in multiple sclerosis or alzheimer's disease than in bullous pemphigoid. J Invest Dermatol. (2019) 139:293-9. doi: 10.1016/j.jid.2018.09.010

35. Varpuluoma O, Jokelainen J, Försti A, Turpeinen M, Timonen M, Huilaja L. Drugs used for neurological and psychiatric conditions increase the risk of bullous pemphigoid: a case-control study. J Am Acad Dermatol. (2019) doi: 10.1016/j.jaad.2019.02.017[Epub ahead of print].

36. Stavropoulos PG, Soura E, Antoniou C. Drug-induced pemphigoid: a review of the literature. J Eur Acad Dermatol Venereol. (2014) 28:1133-40. doi: $10.1111 /$ jdv.12366

37. Pasmatzi E, Monastirli A, Habeos J, Georgiou S, Tsambaos D. Dipeptidyl peptidase-4 inhibitors cause bullous pemphigoid in diabetic patients: report of two cases. Diabetes Care. (2011) 34:e133. doi: 10.2337/dc11-0804

38. Skandalis K, Spirova M, Gaitanis G, Tsartsarakis A, Bassukas ID. Druginduced bullous pemphigoid in diabetes mellitus patients receiving dipeptidyl peptidase-IV inhibitors plus metformin. J Eur Acad Dermatol Venereol. (2012) 26:249-53. doi: 10.1111/j.1468-3083.2011.04062.x

39. Aouidad I, Fite C, Marinho E, Deschamps L, Crickx B, Descamps V. A case report of bullous pemphigoid induced by dipeptidyl peptidase- 4 inhibitors. JAMA Dermatol. (2013) 149:243-5. doi: 10.1001/jamadermatol.2013.1073

40. Attaway A, Mersfelder TL, Vaishnav S, Baker JK. Bullous pemphigoid associated with dipeptidyl peptidase IV inhibitors. A case report and review of literature J Dermatol Case Rep. (2014) 8:24. doi: 10.3315/jdcr.2014.1166

41. Bene J, Jacobsoone A, Coupe P, Auffret M, Babai S, Hillaire-Buys D. Bullous pemphigoid induced by vildagliptin: a report of three cases. Fundamental Clin Pharmacol. (2015) 29:112-4. doi: 10.1111/fcp.12083

42. Mendonça FMI, Martín-Gutierrez FJ, Ríos-Martín JJ, Camacho-Martinez F. Three cases of bullous pemphigoid associated with dipeptidyl peptidase4 inhibitors-one due to linagliptin. Dermatology. (2016) 232:249-53. doi: $10.1159 / 000443330$

43. García M, Aranburu MA, Palacios-Zabalza I, Lertxundi U, Aguirre C. Dipeptidyl peptidase-IV inhibitors induced bullous pemphigoid: a case report and analysis of cases reported in the European pharmacovigilance database. $J$ Clin Pharm Therapeut. (2016) 41:368-70. doi: 10.1111/jcpt.12397

44. Haber R, Fayad AM, Stephan F, Obeid G, Tomb R. Bullous pemphigoid associated with linagliptin treatment. JAMA Dermatol. (2016) 152:224-6. doi: 10.1001/jamadermatol.2015.2939

45. Sakai A, Shimomura Y, Ansai O, Saito Y, Tomii K, Tsuchida Y. Linagliptinassociated bullous pemphigoid that was most likely caused by IgG autoantibodies against the midportion of BP180. Br J Dermatol. (2017) 176:541-3. doi: 10.1111/bjd.15111

46. Esposito I, Moretta G, Peris K, De Simone C. Linagliptin-induced bullous pemphigoid. Int J Dermatol. (2017) 56:1467-9. doi: 10.1111/ijd.13705

47. Yoshiji S, Murakami T, Harashima S, Ko R, Kashima R, Yabe D. Bullous pemphigoid associated with dipeptidyl peptidase-4 inhibitors: a report of five cases. J Diabetes Invest. (2018) 9:445-7. doi: 10.1111/jdi.12695
48. Harada M, Yoneda A, Haruyama S, Yabuki K, Honma Y, Hiura M. Bullous pemphigoid associated with the dipeptidyl peptidase-4 inhibitor sitagliptin in a patient with liver cirrhosis complicated with rapidly progressive hepatocellular carcinoma. Intern Med. (2017) 56:2471-4. doi: 10.2169/internalmedicine.8703-16

49. Oya K, Fujii M, Taguchi S, Nishie W, Izumi K, Shimizu H. Bullous pemphigoid following the replacement of vildagliptin with anagliptin. J Dermatol. (2017) 44:e238-e239. doi: 10.1111/1346-8138

50. Schaffer C, Buclin T, Jornayvaz FR, Cazzaniga S, Borradori L, Gilliet M. Use of dipeptidyl-peptidase IV inhibitors and bullous pemphigoid. Dermatology. (2017) 233:401-3. doi: 10.1159/000480498

51. Fania L, Salemme A, Provini A, Pagnanelli G, Collina MC, Abeni D. Detection and characterization of IgG, IgE, and IgA autoantibodies in patients with bullous pemphigoid associated with dipeptidyl peptidase-4 inhibitors. J Am Acad Dermatol. (2018) 78:592-5. doi: 10.1016/j.jaad.2017.09.051

52. Lindgren O, Varpuluoma O, Tuusa J, Ilonen J, Huilaja L, Kokkonen N. Gliptin-associated bullous pemphigoid and the expression of dipeptidyl peptidase-4/CD26 in bullous pemphigoid. Acta Dermato-Venereol. (2019) 99:602-9. doi: 10.2340/00015555-3166

53. Benzaquen M, Borradori L, Berbis P, Cazzaniga S, Valero R, Richard M. Dipeptidyl peptidase-IV inhibitors, a risk factor for bullous pemphigoid. retrospective multicenter case-control study in France and Switzerland J Am Acad Dermatol. (2018) 78:1090-6. doi: 10.1016/j.jaad.2017.12.038

54. Varpuluoma O, Försti AK, Jokelainen J, Turpeinen M, Timonen M, Huilaja L. Vildagliptin significantly increases the risk of bullous pemphigoid: a Finnish nationwide registry study. J Invest Dermatol. (2018) 138:1659-61. doi: 10.1016/j.jid.2018.01.027

55. Kawaguchi Y, Shimauchi R, Nishibori N, Kawashima K, Oshitani S, Fujiya A. Dipeptidyl peptidase-4 inhibitors-associated bullous pemphigoid: a retrospective study of 168 pemphigoid and 9,304 diabetes mellitus cases. $J$ Diabetes Invest. (2018) 10:392-8. doi: 10.1111/jdi.12877

56. Kridin K, Bergman R. Association of bullous pemphigoid with dipeptidylpeptidase 4 inhibitors in patients with diabetes: estimating the risk of the new agents and characterizing the patients. JAMA Dermatol. (2018) 154:1152-8. doi: 10.1001/jamadermatol.2018.2352

57. Plaquevent M, Tétart F, Fardet L, Ingen-Housz-Oro S, Valleyrie-Allanore L, Bernard P. Higher frequency of dipeptidyl peptidase IV inhibitor intake in bullous pemphigoid patients than in the french general population. J Invest Dermatol. (2019) 139:835-41. doi: 10.1016/j.jid.2018.10.045

58. Lee SG, Lee HJ, Yoon MS, Kim DH. Association of dipeptidyl peptidase 4 inhibitor use with risk of bullous pemphigoid in patients with diabetes. JAMA Dermatol. (2019) 155:172-7. doi: 10.1001/jamadermatol.2018.4556

59. Siegel J, Totonchy M, Damsky W, Berk-Krauss J, Castiglione F Jr, Sznol M. Bullous disorders associated with anti-PD-1 and anti-PD-L1 therapy: a retrospective analysis evaluating the clinical and histopathologic features, frequency, and impact on cancer therapy. J Am Acad Dermatol. (2018) 79:1081-8. doi: 10.1016/j.jaad.2018.07.008

60. Zumelzu C, Alexandre M, Le Roux C, Weber P, Guyot A, Levy A. Mucous membrane pemphigoid, bullous pemphigoid, and anti-programmed death1/programmed death-ligand 1: a case report of an elderly woman with mucous membrane pemphigoid developing after pembrolizumab therapy for metastatic melanoma and review of the literature. Front Med. (2018) 5:268. doi: 10.3389/fmed.2018.00268

61. Waumans Y, Baerts L, Kehoe K, Lambeir AM, De Meester I. The dipeptidyl peptidase family, prolyl oligopeptidase, and prolyl carboxypeptidase in the immune system and inflammatory disease, including atherosclerosis. Front Immunol. (2015) 6:387. doi: 10.3389/fimmu.2015.00387

62. Ohnuma K, Dang NH, Morimoto C. Revisiting an old acquaintance: CD26 and its molecular mechanisms in T cell function. Trends Immunol. (2008) 29:295-301. doi: 10.1016/j.it.2008.02.010

63. Van Lingen RG, Van De Kerkhof P, Seyger M, De Jong E, Van Rens D, Poll M. CD26/dipeptidyl-peptidase IV in psoriatic skin: upregulation and topographical changes. Br J Dermatol. (2008) 158:1264-72. doi: $10.1111 /$ j.1365-2133.2008.08515.x

64. Remm F, Franz W, Brenner C. Gliptins and their target dipeptidyl peptidase 4: implications for the treatment of vascular disease. Eur Heart J Cardiovasc Pharmacother. (2015) 2:185-93. doi: 10.1093/ehjcvp/pvv044 
65. Yazbeck R, Howarth GS, Abbott CA. Dipeptidyl peptidase inhibitors, an emerging drug class for inflammatory disease? Trends Pharmacol Sci. (2009) 30:600-7. doi: 10.1016/j.tips.2009.08.003

66. Brenner C, Franz WM, Kühlenthal S, Kuschnerus K, Remm F, Gross L. DPP-4 inhibition ameliorates atherosclerosis by priming monocytes into M2 macrophages. Int J Cardiol. (2015) 199:163-9. doi: 10.1016/j.ijcard.2015.07.044

67. Bene J, Moulis G, Bennani I, Auffret M, Coupe P, Babai S, et al. Bullous pemphigoid and dipeptidyl peptidase IV inhibitors: a case-noncase study in the French pharmacovigilance database. Br J Dermatol. (2016) 175:296-301. doi: 10.1111/bjd.14601

68. Arai M, Shirakawa J, Konishi H, Sagawa N, Terauchi Y. Bullous pemphigoid and dipeptidyl peptidase 4 inhibitors: a disproportionality analysis based on the Japanese adverse drug event report database. Diabetes Care. (2018) 41:e132. doi: 10.2337/dc18-0210dc18-0210

69. Patsatsi A, Kyriakou A, Meltzanidou P, Trigoni A, Lamprou F, Kokolios M. bullous pemphigoid in patients with DPP-4 inhibitors at the onset of disease: does this differ from common bullous pemphigoid? Eur J Dermatol. (2018) 28:711-3. doi: 10.1684/ejd.2018.3371

70. Izumi K, Nishie W, Mai Y, Wada M, Natsuga K, Ujiie H. Autoantibody profile differentiates between inflammatory and noninflammatory bullous pemphigoid. J Invest Dermatol. (2016) 136:2201-10. doi: 10.1016/j.jid.2016.06.622

71. Horikawa H, Kurihara Y, Funakoshi T, Umegaki-Arao N, Takahashi H, Kubo A. Unique clinical and serological features of bullous pemphigoid associated with dipeptidyl peptidase-4 inhibitors. Br J Dermatol. (2018) 178:1462-3. doi: $10.1111 /$ bjd.16479

72. Ujiie H, Muramatsu K, Mushiroda T, Ozeki T, Miyoshi H, Iwata $H$. HLA-DQB1* 03: 01 as a biomarker for genetic susceptibility to bullous pemphigoid induced by DPP-4 inhibitors. J Invest Dermatol. (2018) 138:1201. doi: 10.1016/j.jid.2017.11.023

73. Kobayashi M, Amagai M, Kuroda-Kinoshita K, Hashimoto T, Shirakata Y, Hashimoto K. BP180 ELISA using bacterial recombinant NC16a protein as a diagnostic and monitoring tool for bullous pemphigoid. J Dermatol Sci. (2002) 30:224-32. doi: 10.1016/S0923-1811(02)00109-3

74. Nakama K, Koga H, Ishii N, Ohata C, Hashimoto T, Nakama T. Clinical and immunological profiles of 14 patients with bullous pemphigoid without IgG autoantibodies to the BP180 NC16A domain. JAMA Dermatol. (2018) 154:347-50. doi: 10.1001/jamadermatol.2017.5465

75. Murrell DF, Daniel BS, Joly P, Borradori L, Amagai M, Hashimoto T. Definitions and outcome measures for bullous pemphigoid: recommendations by an international panel of experts. J Am Acad Dermatol. (2012) 66:479-85. doi: 10.1016/j.jaad.2011.06.032

76. Oyama, N, Setterfield, JF, Powell, AM, Sakuma-Oyama, Y, Albert, S, Bhogal, BS. (2006). Bullous pemphigoid antigen II (BP180) and its soluble extracellular domains are major autoantigens in mucous membrane pemphigoid: the pathogenic relevance to HLA class II alleles and disease severity. Br J Dermatol. 154, 90-98. doi: 10.1111/j.1365-2133.2005.06998.x

77. Lee JB, Liu Y, Hashimoto T. Cicatricial pemphigoid sera specifically react with the most C-terminal portion of BP180. J Dermatol Sci. (2003) 32:59-64. doi: 10.1016/s0923-1811(03)00035-5

78. García-Díez I, España A, Iranzo P. Epitope-spreading phenomena in dipeptidyl peptidase-4 inhibitor-associated bullous pemphigoid. $\mathrm{Br} J$ Dermatol. (2019) 180:1267-8. doi: 10.1111/bjd.17690

79. Mai Y, Nishie W, Izumi K, Yoshimoto N, Morita Y, Watanabe M. Detection of anti-BP 180 NC 16A autoantibodies after the onset of dipeptidyl peptidase-IV inhibitor-associated bullous pemphigoid: a report of three cases. Br J Dermatol. (2018a) 179:790-1. doi: 10.1111/bjd. 16656

80. Takama H, Yoshida M, Izumi K, Yanagishita T, Muto J, Ohshima Y. Dipeptidyl peptidase-4 inhibitor-associated bullous pemphigoid: recurrence with epitope spreading. Acta Dermato-Venereol. (2018) 98:983-4. doi: $10.2340 / 00015555-3010$
81. Forssmann U, Stoetzer C, Stephan M, Kruschinski C, Skripuletz T, Schade J. Inhibition of CD26/dipeptidyl peptidase IV enhances CCL11/eotaxinmediated recruitment of eosinophils in vivo. J Immunol. (2008) 181:1120-7. doi: 10.4049/jimmunol.181.2.1120

82. Gonzalez-Gronow M, Kaczowka S, Gawdi G, Pizzo SV. Dipeptidyl peptidase IV (DPP IV/CD26) is a cell-surface plasminogen receptor. Front Biosci. (2008) 13:1610-8. doi: $10.2741 / 2785$

83. Hofmann SC, Voith U, Schönau V, Sorokin L, Bruckner-Tuderman L, Franzke C. Plasmin plays a role in the in vitro generation of the linear IgA dermatosis antigen LADB97. J Invest Dermatol. (2009) 129:1730-9. doi: 10.1038/jid.2008.424

84. Nishimura M, Nishie W, Shirafuji Y, Shinkuma S, Natsuga K, Nakamura H. Extracellular cleavage of collagen XVII is essential for correct cutaneous basement membrane formation. Hum Mol Genet. (2015) 25:328-39. doi: $10.1093 / \mathrm{hmg} / \mathrm{ddv} 478$

85. Okauchi Y, Tomoda Y, Takata M, Deguchi A, Takata M, Takenoshita Y. Pemphigus vulgaris developing after 6-month treatment with a dipeptidyl peptidase-4 inhibitor: a case report. J Dermatol. (2018) 45:e40. doi: 10.1111/1346-8138.14076

86. Long M, Cai L, Li W, Zhang L, Guo S, Zhang R. DPP-4 inhibitors improve diabetic wound healing via direct and indirect promotion of epithelialmesenchymal transition and reduction of scarring. Diabetes. (2018) 67:51831. doi: $10.2337 / \mathrm{db} 17-0934$

87. Nishie W, Lamer S, Schlosser A, Licarete E, Franzke C, Hofmann SC. Ectodomain shedding generates neoepitopes on collagen XVII, the major autoantigen for bullous pemphigoid. J Immunol. (2010) 185:4938-47. doi: 10.4049/jimmunol.1001524

88. Tasanen K, Tunggal L, Chometon G, Bruckner-Tuderman L, Aumailley M. Keratinocytes from patients lacking collagen XVII display a migratory phenotype. Am J Pathol. (2004) 164:2027-38. doi: 10.1016/S0002-9440(10)63762-5

89. Mathias RA, Wang B, Ji H, Kapp EA, Moritz RL, Zhu H. Secretome-based proteomic profiling of ras-transformed MDCK cells reveals extracellular modulators of epithelial-mesenchymal transition. J Proteome Res. (2009) 8:2827-37. doi: 10.1021/pr8010974

90. Thielitz A, Vetter RW, Schultze B, Wrenger S, Simeoni L, Ansorge S. Inhibitors of dipeptidyl peptidase IV-like activity mediate antifibrotic effects in normal and keloid-derived skin fibroblasts. J Invest Dermatol. (2008) 128:855-66. doi: 10.1038/sj.jid.5701104

91. Lo Schiavo A, Ruocco E, Brancaccio G, Caccavale S, Ruocco V, Wolf R. Bullous pemphigoid: etiology, pathogenesis, and inducing factors: facts and controversies. Clin Dermatol. (2013) 31:391-9. doi: 10.1016/j.clindermatol.2013.01.006

92. Mai Y, Nishie W, Sato K, Hotta M, Izumi K, Ito K. Bullous pemphigoid triggered by thermal burn under medication with a dipeptidyl peptidase-IV inhibitor: a case report and review of the literature. Front Immunol. (2018b) 9:542. doi: 10.3389/fimmu.2018.00542

93. Nishie W, Tasanen K. Gliptin-associated bullous pemphigoid: a valuable model of the mechanism of breakdown of immune tolerance against BP180. The Journal of Investigative Dermatology. (2019) 139:755-6. doi: 10.1016/j.jid.2018.11.025

Conflict of Interest Statement: The authors declare that the research was conducted in the absence of any commercial or financial relationships that could be construed as a potential conflict of interest.

Copyright (C) 2019 Tasanen, Varpuluoma and Nishie. This is an open-access article distributed under the terms of the Creative Commons Attribution License (CC BY). The use, distribution or reproduction in other forums is permitted, provided the original author(s) and the copyright owner(s) are credited and that the original publication in this journal is cited, in accordance with accepted academic practice. No use, distribution or reproduction is permitted which does not comply with these terms. 